\title{
Reporting myocardial flow reserve with PET. Ready or not, here it is! But walk before you fly!
}

\author{
Daniel Juneau, MD, ${ }^{\text {a }}$ Robert A. deKemp, PhD, ${ }^{b}$ and Rob S. B. Beanlands, $M^{b}$ \\ a Nuclear Medicine, Centre Hospitalier de l'Université de Montréal (CHUM), Montreal, Canada \\ b Division of Cardiology, Department of Medicine, National Cardiac PET Centre, University of \\ Ottawa Heart Institute, Ottawa, ON, Canada
}

Received Sep 25, 2017; accepted Sep 26, 2017

doi: 10.1007/s12350-017-1087-5

Relative perfusion images have been the mainstay of myocardial perfusion imaging (MPI) for more than 30 years. While positron emission tomography (PET) tracers for cardiac imaging have been available for more than 4 decades, cardiac PET was mostly a research tool until the last decade, when the expansion of PET oncological imaging saw a significant improvement in the clinical availability of this technology. Advances in acquisition technology have also enabled the simultaneous measurement of relative perfusion and absolute flow. Amongst its many advantages over single-photon emission computed tomography (SPECT) MPI, PET permits routine, accurate, and reproducible non-invasive measurement of myocardial blood flow (MBF), in absolute units $(\mathrm{mL} / \mathrm{min} / \mathrm{g}$ of myocardium), which can be measured at rest and peak stress, and from which myocardial flow reserve (MFR; the ratio of stress MBF divided by rest MBF) can be calculated. Both stress MBF and MFR have since demonstrated their diagnostic and prognostic capacity in multiple settings and populations. They have become firmly established as reliable clinical research tools. In this issue of the Journal of Nuclear Cardiology, the question of whether or not these tools and metrics are ready for prime-time use as an integral part of clinical reporting is debated. Opposing views are presented, with M. Di Carli ${ }^{1}$ defending the "pro" position and H. Schelbert ${ }^{2}$ defending the "con", position.

Di Carli presents 2 main arguments for the added value of MBF and MFR in routine clinical reporting: an increased accuracy for the detection of obstructive

\footnotetext{
Reprint requests: Rob S. B. Beanlands, MD, Division of Cardiology, Department of Medicine, National Cardiac PET Centre, University of Ottawa Heart Institute, 40 Ruskin Street, Ottawa, ON K1Y 4W7, Canada; rbeanlands@ottawaheart.ca

J Nucl Cardiol 2018;25:164-8.

$1071-3581 / \$ 34.00$

Copyright (C) 2017 American Society of Nuclear Cardiology.
}

coronary artery disease $(\mathrm{CAD})$ and better prognostic information for risk stratification. Increased accuracy is achieved mainly because absolute quantification helps overcome two of the most important shortcomings of conventional relative MPI; it increases the ability to detect multivessel disease, which can sometimes present with a so-called "balanced ischemia" pattern ${ }^{3,4}$, and it enables the detection of non-obstructive atherosclerosis (epicardial lesions of less than 50\%), which cannot be assessed using relative MPI alone, but still carries an increased risk of cardiac events. ${ }^{5-7}$ Regarding the prognostic value of MBF and MFR, Di Carli presents the available evidence, which clearly demonstrates that MFR and stress MBF are both powerful prognostic tools, with incremental and independent information from relative MPI findings. ${ }^{6,7} \mathrm{He}$ does acknowledge the limitations, including the lack of a true absolute "one size fits all" cut-off value for normalcy, for either stress MBF or MFR, and the existence of clinical conditions which can limit the accuracy or usefulness of these metrics.

Arguing the "con" position, Schelbert first raises the issue of the appropriateness criteria. He, rightfully, points out that there is a dearth of data regarding the ability of MBF and MFR to influence clinical decision making, and whether cardiac risk re-classification using these metrics has a significant impact on pretest diagnostic and therapeutic decisions. Schelbert points out the complexity of the many autoregulatory forces and factors which impact the vasodilatator capacity and response. He discusses how this complexity likely plays a part in the variability of MBF measurements, and the variability of MFR in "normal" individuals. He also raises concerns over the importance of reviewing the technical aspects of flow measurement, and the possibility of drug-related antagonistic effects such as caffeine. He suggests that further work will be required to better harmonize and define what constitutes a normal 
or an abnormal flow response. He then concludes by saying that while MBF and MFR measurements can significantly contribute to the diagnosis and management of CAD, further data are required before they can be fully incorporated in the reporting of PET MPI.

Interestingly, both authors cite many of the same publications. There is no dispute regarding the data itself, which clearly supports the diagnostic and prognostic value of stress MBF and MFR. Rather, the debate is how the nuclear cardiology community should proceed at this time with MBF and MFR as a clinical tool. The contentious areas mostly concern the technical aspects of MBF and MFR measurement, the definition of normalcy, and the appropriateness/added value of these metrics in clinical decision making.

Regarding the technical aspects, several studies have shown good test-retest repeatability of stress MBF and MFR measurements (day-to-day coefficient of variation $(\mathrm{CoV})=20 \%)$ and reproducibility among laboratories $(<10 \% \mathrm{CoV}$ when using similar methods). ${ }^{8-12}$ Recently, Kitkungvan et al and Klein et al demonstrated very good methodological repeatability $(<10 \% \mathrm{CoV})$ over short time intervals between scans. ${ }^{11-13}$ Studies have also shown, for both ${ }^{13} \mathrm{~N}$-ammonia and ${ }^{82} \mathrm{Rb}$, the two most commonly used PET perfusion tracers, that MFR values exhibit an excellent correlation between different software packages when the same compartment model is used ${ }^{14-16}$ although the coefficients of variation are higher for absolute flow measurements compared to relative perfusion imaging because of added biological variability. ${ }^{12}$

Schelbert also mentions the possibility of falsely abnormal (impaired) MFR due to antagonistic effect on the vasodilatator effect from drugs or caffeine-containing products. While this is indeed a possibility, this is not an argument against the use of MFR in routine clinical work, but rather an argument for it. For example, if a patient who had not undergone caffeine withdrawal as instructed was to undergo relative MPI, the study might be falsely interpreted as normal, while the same patient undergoing MBF and MFR measurement would likely demonstrate an absence of MBF change between rest and stress studies. An experienced imager would recognize that a patient with non-responsiveness to pharmacological stress does not demonstrate the features expected with severe multivessel CAD. Global and regional flows are at or near 1.0, with homogeneous rather than heterogeneous MFR; uptake similar to rest and no new defects; little or no hemodynamic changes; and no high-risk response features (e.g., ECG changes, stress-induced perfusion defects, wall motion abnormalities, TID, RV uptake). ${ }^{17,18}$ In addition to RPP changes, a splenic "switch-off" response can also be seen as an indicator of adequate vasodilator stress, i.e., reduced tracer uptake in the spleen due to the differential effects of adenosine on the spleen (seen with dipyridamole or adenosine but not regadenoson). ${ }^{19}$ With relative MPI only, it is not possible to determine nonresponsiveness which would otherwise contribute to a false-negative study if disease were missed. When nonresponsiveness is identified on quantitative PET flow studies, a repeat test with prolonged caffeine abstinence (e.g., 72 hours) or with an alternate pharmacologic stress agent such as dobutamine would be recommended.

The lack of a clearly defined cut-off value for normalcy can be problematic. In nuclear cardiology, we pride ourselves in making such definitive distinctions between normal and abnormal. With the wide range of physiological flow values and their significant variance, ${ }^{11,12}$ as well as effects of age, sex, resting hemodynamics, and risk factors, for example, a standard normal value becomes harder to define and may be different for different populations. However, this may be less important at the extreme values. As noted by both Schelbert and Di Carli, ${ }^{1,2}$ a MFR value of $<1.5$, either in a single territory or in multiple territories, has been strongly associated with obstructive CAD and cardiac events, while a globally " "normal', stress MBF and MFR > 2.0 suggest an excellent prognosis even in patients with known CAD. ${ }^{4,6,7}$ Since a patient with single-vessel CAD may still have global MFR $>2.0$, caution is needed in reporting flow data in these circumstances. It is important for the imager and the referring physician to understand that abnormal relative perfusion may account for a symptomatic obstructive lesion and still have normal global flow reserve. When reporting flow data in these circumstances, the imager should qualify the flow data interpretation and mention the regional heterogeneity or consider not reporting it to avoid what may appear to be a conflicting message. There is a need for standardization of reporting and perhaps the development of new nomenclature whereby a global flow reserve value of $>2.0$ is not defined as "normal" but rather "low-risk."

Further, it is extremely important that these metrics not be considered as independent; they are part of a complete assessment of coronary physiology — the full PET MPI study which includes everything from the patient's pretest probability and risk factors, the stress ECG, the relative MPI findings (uptake defects, transient ischemic dilatation), LV function, and the CTAC calcium findings. Stress MBF and MFR measurements do not replace or override these findings; they complement and enhance them.

Finally, the information required to obtain and measure MBF and MFR is, in a sense, "free", when acquired during pharmacologic stress and using PET instrumentation that is capable of accurate first-pass imaging. ${ }^{20} \mathrm{MBF}$ quantification does not require any 
Table 1. Conditions for the safe incorporation of myocardial flow quantification in routine clinical reporting

Flow data should be considered in conjunction with

- History, ECG, calcium, perfusion, LV size and function, RV uptake, TID

Interpreting physicians and PET center teams and their physicians should have

- Significant experience and knowledge of flow quantification, its strengths and limitations

- Thorough understanding of the quality controls and assurance involved

Interpreting physicians should

- Recognize the limitations and cautionary conditions, such as patients with

- Prior coronary artery bypass surgery

- Severe renal dysfunction

- Moderate to severe LV dysfunction

- Large regions of myocardial scar

- Recognize non-responsiveness to pharmacological stress

- Keep the referring physicians in mind and

- Be aware of their knowledge and understanding of the value and limitations of flow measurements

- Understand what question they are asking and how flow measurements can or cannot help

- Remember that they may benefit from direct correspondence in complex cases

additional patient procedure and does not expose the patient to additional risk or radiation. In the same way, LV function and wall motion became possible using ECG-gated SPECT, adding important prognostic information to the whole report; so too will flow data provide additional valuable information to PET MPI. This information, if taken in proper context, enhances accuracy and prognostic value which should impact decisions for angiography, and help direct interventional vs. medical therapy.

As noted by our debaters, there is a paucity of data on the impact of MFR on clinical decision making, downstream diagnostic testing, and treatment. Whether such clinical decisions impact outcome also depends on the effectiveness of the therapy chosen. ${ }^{21}$ Ideally, randomized controlled trials of strategies using PET flow data versus standard-of-care would provide definitive answers. However, such trial design is extremely difficult to implement and, as noted, depends on the effectiveness of the therapy selected. In the meantime, reclassifying patients using MFR (as demonstrated by Murthy et $\mathrm{al}^{7}$ ) provides high clinical utility in defining risk, which in itself should direct the clinician to more or less aggressive interventions and management strategies. Finally, there are higher risk interventions (PCI and $\mathrm{CABG}$ ) for obstructive disease, necessitating an important decision point where imaging has demonstrated a crucial role. Indeed, functional measurements of flow, such as fractional flow reserve (FFR)-directed therapy, have had impact on outcomes (albeit FFR is an invasive measurement). ${ }^{22}$ On the other hand, defining non-obstructive disease, while useful, currently has no specific interventional or medical therapy recommendations associated with it, short of risk factor modification. Evidence is rapidly emerging on the importance of microvascular disease in the development and progress of atherosclerosis including sex differences, heart failure with preserved ejection fraction, and transplant vasculopathy. ${ }^{23}$ As greater understanding of these disease states emerges, novel therapies may be forthcoming, in which case flow quantification with non-invasive PET imaging will be at the focal point of decision making.

Our debaters also note the need for the development of criteria for quality control, interpretation, and reporting. There are recent guidelines and position statements that will help in this regard, ${ }^{18}$ but there is still work to be done to enable measurements that are fully interchangeable between sites. So, are PET flow data ready or not for clinical use? Ready to walk, yes, but not to run. The first steps are the most important and need to occur carefully so PET flow 'does not stumble.' Clinical interpretation needs to be performed under the right conditions (Table 1). At this time, reporting should be confined to experienced centers, where the combination of both experienced and educated imagers and referring physicians can be achieved. Part of this education is incumbent to the interpreting physician who will likely need to keep in mind the degree of familiarity of the referring physician and adjust the level of details and guidance in the report accordingly. A simple numerical cut-off value might well be enough in an experienced reference center, when dealing with a physician or team who are accustomed to using these metrics, but more detailed information/guidance will need to be provided by the interpreting physician when interacting with a less experienced team. As more and more physicians 
and centers embrace the possibilities afforded by flow data, our knowledge will continue to grow, and the capacity for better "'harmonization" of reporting and interpretation will increase. Recent advances in blood flow quantification using SPECT $^{24-26}$ may greatly increase access to flow measurements, which would further accelerate clinical integration. Currently, however, there are far less data available on SPECT than PET quantification, and this technology remains purely a research tool at this time.

In conclusion, PET MBF and MFR measurements provide useful data that enhance both accuracy and risk stratification for PET MPI. Evaluation of flow data and its reporting in clinical practice should consider the specific incremental information to assist with clinical decision making; explain the relevance of any added information; and recognize cautionary situations including non-responders and certain clinical scenarios (Table 1). Keys to successful implementation and getting the most out of adding flow data to a reporting strategy include the experience of the imaging team as well as the knowledge and understanding of referring physicians. However, research must continue. We need to understand the full clinical value of flow quantification; for example, the role and potential treatments of microvascular disease and, even more importantly, the role of flow measures in selecting and monitoring revascularization therapies and indeed the impact of these therapy decisions on cardiac outcomes. As demonstrated successfully for FFR measurements of hemodynamic significance ${ }^{22,27}$ and FDG PET viability imaging, ${ }^{28}$ quantitative measurements will become essential in clinical reports when they can be used reliably to make concrete recommendations for effective treatments which have been shown to improve patient outcome. So PET MBF/MFR reporting is ready to 'walk.' With further research, clinical PET flow reporting will be able to accelerate its pace to 'run' and who knows, may one day 'fly'!

\section{Disclosures}

DJ. has no disclosures related to this work. R.S.B.B. is or has been a consultant for and received grant funding from Lantheus Medical Imaging, GE, and Jubilant DraxImage. R.A.dK is a consultant for Jubilant DraxImage and receives technology license revenues from Jubilant DraxImage and INVIA Medical Imaging Solutions.

\section{References}

1. Di Carli MF. Measurement of MBF by PET is ready for prime time as an integral part of clinical reports in diagnosis and risk assessment of patients with known or suspected CAD-PRO. J Nucl Cardiol. 2017. https://doi.org/10.1007/s12350-017-1035-4.

2. Schelbert H. Measurement of MBF by PET is ready for prime time as an integral part of clinical reports in diagnosis and risk assessment of patients with known or suspected CAD For prime time not yet-need impact and certainty. J Nucl Cardiol. 2017. https://doi.org/10.1007/s12350-016-0423-5.

3. Parkash R, deKemp RA, Ruddy TD, Kitsikis A, Hart R, Beauchesne L, Beauschene L, Williams K, Davies RA, Labinaz M, Beanlands RSB. Potential utility of rubidium 82 PET quantification in patients with 3-vessel coronary artery disease. J Nucl Cardiol Off Publ Am Soc Nucl Cardiol. 2004;11:440-9.

4. Ziadi MC, Dekemp RA, Williams K, Guo A, Renaud JM, Chow BJW, Klein R, Ruddy TD, Aung M, Garrard L, Beanlands RSB. Does quantification of myocardial flow reserve using rubidium-82 positron emission tomography facilitate detection of multivessel coronary artery disease? J Nucl Cardiol Off Publ Am Soc Nucl Cardiol. 2012;19:670-80.

5. Taqueti VR, Hachamovitch R, Murthy VL, Naya M, Foster CR, Hainer J, Dorbala S, Blankstein R, Di Carli MF. Global coronary flow reserve is associated with adverse cardiovascular events independently of luminal angiographic severity and modifies the effect of early revascularization. Circulation. 2015;131:19-27.

6. Ziadi MC, Dekemp RA, Williams KA, Guo A, Chow BJW, Renaud JM, Ruddy TD, Sarveswaran N, Tee RE, Beanlands RSB. Impaired myocardial flow reserve on rubidium-82 positron emission tomography imaging predicts adverse outcomes in patients assessed for myocardial ischemia. $\mathrm{J}$ Am Coll Cardiol. 2011;58:740-8.

7. Murthy VL, Naya M, Foster CR, Hainer J, Gaber M, Di Carli G, Blankstein R, Dorbala S, Sitek A, Pencina MJ, Di Carli MF. Improved cardiac risk assessment with noninvasive measures of coronary flow reserve. Circulation. 2011;124:2215-24.

8. Klein R, Renaud JM, Ziadi MC, Thorn SL, Adler A, Beanlands $\mathrm{RS}$, deKemp RA. Intra- and inter-operator repeatability of myocardial blood flow and myocardial flow reserve measurements using rubidium-82 pet and a highly automated analysis program. $\mathrm{J}$ Nucl Cardiol Off Publ Am Soc Nucl Cardiol. 2010;17:600-16.

9. El Fakhri G, Kardan A, Sitek A, Dorbala S, Abi-Hatem N, Lahoud Y, Fischman A, Coughlan M, Yasuda T, Di Carli MF. Reproducibility and accuracy of quantitative myocardial blood flow assessment with (82)Rb PET: Comparison with (13)N-ammonia PET. J Nucl Med Off Publ Soc Nucl Med. 2009;50:1062-71.

10. Schindler TH, Zhang X-L, Prior JO, Cadenas J, Dahlbom M, Sayre J, Schelbert HR. Assessment of intra- and interobserver reproducibility of rest and cold pressor test-stimulated myocardial blood flow with (13)N-ammonia and PET. Eur J Nucl Med Mol Imaging. 2007;34:1178-88.

11. Kitkungvan D, Johnson NP, Roby AE, Patel MB, Kirkeeide R, Gould KL. Routine clinical quantitative rest stress myocardial perfusion for managing coronary artery disease: Clinical relevance of test-retest variability. JACC Cardiovasc Imaging. 2017;10:56577.

12. Beanlands RSB, Chong A-Y, deKemp RA. Clinical PET flow reserve imaging: Is there precision to treat patients or populations? JACC Cardiovasc Imaging. 2017;10:578-81.

13. Klein R, Ocneanu A, Renaud JM, Ziadi MC, Beanlands RSB, deKemp RA. Consistent tracer administration profile improves test-retest repeatability of myocardial blood flow quantification with (82) Rb dynamic PET imaging. J Nucl Cardiol Off Publ Am Soc Nucl Cardiol. 2016. https://doi.org/10.1007/s12350016-0698-6.

14. Nesterov SV, Deshayes E, Sciagrà R, Settimo L, Declerck JM, Pan X-B, Yoshinaga K, Katoh C, Slomka PJ, Germano G, Han C, 
Aalto V, Alessio AM, Ficaro EP, Lee BC, Nekolla SG, Gwet KL, deKemp RA, Klein R, Dickson J, Case JA, Bateman T, Prior JO, Knuuti JM. Quantification of myocardial blood flow in absolute terms using (82)Rb PET imaging: The RUBY-10 Study. JACC Cardiovasc Imaging. 2014;7:1119-27.

15. Slomka PJ, Alexanderson E, Jácome R, Jiménez M, Romero E, Meave A, Le Meunier L, Dalhbom M, Berman DS, Germano G, Schelbert H. Comparison of clinical tools for measurements of regional stress and rest myocardial blood flow assessed with $13 \mathrm{~N}$ ammonia PET/CT. J Nucl Med Off Publ Soc Nucl Med. 2012;53: 171-81.

16. Dekemp RA, Declerck J, Klein R, Pan X-B, Nakazato R, Tonge C, Arumugam P, Berman DS, Germano G, Beanlands RS, Slomka PJ. Multisoftware reproducibility study of stress and rest myocardial blood flow assessed with 3D dynamic PET/CT and a 1-tissuecompartment model of $82 \mathrm{Rb}$ kinetics. J Nucl Med Off Publ Soc Nucl Med. 2013;54:571-7.

17. Juneau D, Erthal F, Ohira H, Mc Ardle B, Hessian R, deKemp RA, Beanlands RSB. Clinical PET myocardial perfusion imaging and flow quantification. Cardiol Clin. 2016;34:69-85.

18. Dilsizian V, Bacharach SL, Beanlands RS, Bergmann SR, Delbeke D, Dorbala S, Gropler RJ, Knuuti J, Schelbert HR, Travin MI. ASNC imaging guidelines/SNMMI procedure standard for positron emission tomography (PET) nuclear cardiology procedures. J Nucl Cardiol Off Publ Am Soc Nucl Cardiol. 2016;23:1187-226.

19. Bami K, Tewari S, Guirguis F, Garrard L, Guo A, Ruddy TD, Beanlands RS, deKemp RA, Chow BJ, Dwivedi G. Prognostic value of splenic response ratio in rubidium- 82 positron emission tomography myocardial perfusion imaging. Circulation. 2016;134: A17358-A17358.

20. Renaud JM, Yip K, Guimond J, Trottier M, Pibarot P, Turcotte E, Maguire C, Lalonde L, Gulenchyn K, Farncombe T, Wisenberg G, Moody J, Lee B, Port SC, Turkington TG, Beanlands RS, deKemp RA. Characterization of 3-dimensional PET systems for accurate quantification of myocardial blood flow. J Nucl Med Off Publ Soc Nucl Med. 2017;58:103-9.

21. Mc Ardle B, Shukla T, Nichol G, deKemp RA, Bernick J, Guo A, et al. Long-term follow-up of outcomes with F-18-fluorodeoxyglucose positron emission tomography imaging-assisted management of patients with severe left ventricular dysfunction secondary to coronary disease. Circ Cardiovasc Imaging. 2016;9: e004331.

22. Tonino PAL, De Bruyne B, Pijls NHJ, Siebert U, Ikeno F, van't Veer M, Klauss V, Manoharan G, Engstrøm T, Oldroyd KG, Ver Lee PN, MacCarthy PA, Fearon WF. Fractional flow reserve versus angiography for guiding percutaneous coronary intervention. N Engl J Med. 2009;360:213-24.

23. Taqueti VR, Shaw LJ, Cook NR, Murthy VL, Shah NR, Foster CR, Hainer J, Blankstein R, Dorbala S, Di Carli MF. Excess cardiovascular risk in women relative to men referred for coronary angiography is associated with severely impaired coronary flow reserve, not obstructive disease. Circulation. 2017;135:566-77.

24. Wells RG, Marvin B, Poirier M, Renaud JM, deKemp RA, Ruddy TD. Optimization of SPECT measurement of myocardial blood flow with corrections for attenuation, motion, and blood-binding compared to PET. J Nucl Med Off Publ Soc Nucl Med. 2017. https://doi.org/10.2967/jnumed.117.191049.

25. Klein R, Hung G-U, Wu T-C, Huang W-S, Li D, deKemp RA, Hsu B. Feasibility and operator variability of myocardial blood flow and reserve measurements with ${ }^{99} \mathrm{mTc}$-sestamibi quantitative dynamic SPECT/CT imaging. J Nucl Cardiol Off Publ Am Soc Nucl Cardiol. 2014;21:1075-88.

26. Shrestha U, Sciammarella M, Alhassen F, Yeghiazarians Y, Ellin J, Verdin E, Boyle A, Seo Y, Botvinick EH, Gullberg GT. Measurement of absolute myocardial blood flow in humans using dynamic cardiac SPECT and 99mTc-tetrofosmin: Method and validation. J Nucl Cardiol Off Publ Am Soc Nucl Cardiol. 2017;24:268-77.

27. De Bruyne B, Pijls NHJ, Kalesan B, Barbato E, Tonino PAL, Piroth Z, Jagic N, Möbius-Winkler S, Rioufol G, Witt N, Kala P, MacCarthy $\mathrm{P}$, Engström T, Oldroyd KG, Mavromatis K, Manoharan G, Verlee P, Frobert O, Curzen N, Johnson JB, Jüni P, Fearon WF. Fractional flow reserve-guided PCI versus medical therapy in stable coronary disease. N Engl J Med. 2012;367:9911001.

28. Abraham A, Nichol G, Williams KA, Guo A, deKemp RA, Garrard $\mathrm{L}$, et al. 18F-FDG PET imaging of myocardial viability in an experienced center with access to 18F-FDG and integration with clinical management teams: The Ottawa-FIVE substudy of the PARR 2 trial. J Nucl Med Off Publ Soc Nucl Med. 2010;51:567-74. 